\title{
PURPOSE - PROCESS - PEOPLE A LEAN APPROACH TO BIOMEDICAL MANUFACTURING
}

\author{
F-J. Kahlen \\ Department of Mechanical Engineering \\ University of Cape Town, South Africa \\ fj.kahlen@uct.ac.za
}

\begin{abstract}
Opportunities to improve production processes and access to markets through the implementation of lean manufacturing in biomedical manufacturing are presented. The importance of a unified definition of manufacturing, to which biomedical manufacturing is party, is emphasized, and the theory of "lean", summarized as "purpose, process, people", is elaborated. The requirements for the creation of value through the creation of flow and the elimination of wastes are highlighted in the context of biomedical manufacturing. Finally, case studies are presented to illustrate the approaches to "purpose, process, people".

\section{OPSOMMING}

Geleenthede vir die verbetering van produksieprosesse en marktoegang via die implementering van skraalvervaardiging in die biomediese vervaardigingsbedryf word voorgehou. Aandag word geskenk aan die betekenis van terme soos "skraal, doel, proses, menes" in die konteks van biomediese vervaardiging. Waardeskepping, vloei en vermorsing word onder die loep geneem. Gevallestudies word ter illustrasie van begrippe aangebied.
\end{abstract}




\section{INTRODUCTION AND BACKGROUND}

Biomedical manufacturing describes manufacturing operations that take place in a very challenging environment where quality standards are very high and where tolerance to faulty equipment or devices is nearly zero. The definition of "manufacturing" itself, however, is difficult because of the nature of the various industries in which manufacturing takes place. In the fabrication and assembly of a product, however, it is the rule rather then the exception that a product is made up from several components that are produced by a number of different industries. It would therefore be beneficial to have a common definition of what every participant understands "manufacturing" to be, to ensure that everyone is working off the same platform.

The US Census Bureau's North American Industry Classification System (NAICS) [1] classifies an establishment as being in the manufacturing sector if it is "engaged in the mechanical, physical, or chemical transformation of materials, substances, or components into new products." This definition is very broad; even preparing fastfood burgers would have to be considered manufacturing according to this definition. It therefore requires further clarification.

The FDA's definition of manufacturing [2] is equally broad and even ambiguous. Section 820.3 defines a manufacturer as "any person who designs, manufactures, fabricates, assembles, or processes a finished device". According to this definition, a supplier of a semi-finished product would not be a manufacturer. However, a company that produces components that will be used in a dialysis machine will certainly be subject to the same quality standards and regulations as the manufacturer of the dialysis machine itself. The FDA then qualifies its own definition by stating that a "Manufacturer includes but is not limited to those who perform the functions of contract sterilization, installation, relabeling, remanufacturing, repacking, or specification development, and initial distributors of foreign entities performing these functions".

The definitions presented by the Census Bureau and by the FDA refer to manufacturing as a set of operations, without unambiguously defining the term "manufacturing". The definitions neglect, for example, the importance of quality control and continuous improvement of production processes in manufacturing. With regard to the biomedical industry, the effects of this short-coming will make themselves felt as the industry matures and manufacturing in this industry is subjected to cost-cutting and continuous quality improvements. This different manufacturing approach is already being practised today in the automotive or semiconductor industry, under the headline of "lean manufacturing".

\section{LEAN MANUFACTURING}

Lean manufacturing originated at Toyota in Japan in the 1950s [3], as a response to the short-comings of the traditional batch-and-queue mass production approach practised in the automotive industry. These short-comings included a number of factors, most notably the enormous tie-up of working capital in inventories and work-in-process, the amount of rework to be carried out before a vehicle can be sold to the customer, the inability to respond to changing consumer demands, and 
the unwillingness of narrow-skilled employees to improve production processes, for fear of losing their jobs in the process. The lean manufacturing approach pioneered by Toyota has come to be known as the Toyota Production System (TPS). The system can be characterized by three key elements: purpose, process, people. At the center of the TPS is the creation of value, from the perspective of the customer. The purpose of Toyota's operations then is the production of motor vehicles that the customer wants, as opposed to those which the company thinks the customer will want. The effect of this perspective is that it reverses the manufacturing process: raw materials, parts and components are not pushed through the factory, but are pulled by the customer. In order to respond to changing customer demands, Toyota's operation had to develop highly flexible processes, allowing quick changeover times to accommodate these customer demands (vehicle colour, vehicle customization, etc.). If a process must be set up in a way that it creates value for the customer, a critical parameter is introduced into a company's operation: the flow of a product. If a product flows through assembly, then it greatly improves response to customer orders and reduces the tie-up of working capital referred to above. Product flows, among other benefits, reduce delivery times to the customer. The pull of the customer ensures that only those products or services are built or provided that are actually demanded by the customer. This frees up capacity for new product development. Additionally, it enables the companies to increase their product diversity, which is a typical benefit of lean thinking [3]. In order to operate these new processes, the employees (i.e., people) had to be (a) equipped with a much broader skill set, (b) empowered to make decisions while they assembled the vehicle, and (c) helped to eliminate wasteful steps along the path of production. These decisions concerned how to arrange the assembly steps and what to do with defective components received from upstream processes (in-house or suppliers).

It is important to recognize the order in which lean manufacturing proceeds. The reduction of waste (i.e., cost reduction) may take place only after flow of the product has been created. Cost reduction in itself is a valuable approach, but the amount of wasteful activity in an operation will only become fully visible once product flow has been introduced.

TPS has been copied and adapted since the 1980s by nearly all Western automotive OEMs. The most visible effects to the consumer include an increase in product diversity and a reduction of inventories.

The author therefore offers the following definition of manufacturing: "Manufacturing is a team process of creating more than one semi-finished or finished consumer product out of materials, substances or components through mechanical, physical or chemical treatment or transformation. In the ideal situation, manufacturing encompasses a systematic approach to flowing the product at the pull of the customer in pursuit of perfection, identifying and eliminating waste through continuous improvement."

This definition offers several advantages over those described before. First, this definition is not specifying a particular target industry. It is therefore universally applicable to OEMs as well as to suppliers of various disciplines, such as electronics, mechatronics, polymer sciences, packaging, or product sterilization. Proceeding in this way ensures that all participants in product development and sales are 
proceeding from the same platform. Second, the definition demands that the product flows, and that it does so at the pull of the customer. Third, this definition challenges the participants continuously to improve their production processes. If the quality of a production process is improved, then the contingencies for product liability can be reduced as well, thereby freeing up capital for innovations and reducing overall rising health costs [4]. Examples of such paradigm shifts and the associated changes in the manufacturing processes will be presented below. The "pursuit of perfection" implies that this is a never-ending process, as there are always wastes (waiting, rework, transport, inventory, etc.) involved with operations.

The author's position therefore is that manufacturing in the biomedical industry is certainly subject to industry-inherent liability and legal, volumetric, quality, biological and other constraints. The flow of the value stream, however, must be mapped, followed and optimized like in any other industry.

\section{Purpose - creating value for consumers in unregulated markets}

An example of an unregulated medical device market is South Africa [5]. The general requirement of end users, such as private hospitals, is that the products imported into South Africa either are FDA-approved or carry the CE-mark. This applies particularly to high-risk products such as pacemakers or CT scans. Such electro-mechanical devices today must be registered with the Radiation Control Directorate (DRC) under the Ministry of Health. To import a product into South Africa, the company must submit a government-issued form, together with a manufacturer-issued colour brochure of the imported product, a letter of appointment stating that the importer is an authorized representative of the manufacturer, as well as EC certificates and the EC Declaration of Conformity issued by the manufacturer. Duties are not payable on medical and laboratory equipment. However, all imported items are subject to the value-added tax (VAT) applicable at the time of importation.

Monitoring the safe use of radiation equipment comes under the purview of the DRC. For this purpose, regular inspections are carried out at medical institutions and industrial premises in order to ensure that patients, personnel, and members of the public are protected from radiation.

Regulations for medical devices are currently being drafted. The European medical devices directive has been used as a basis for the classification of products. Only products with either FDA approval or CE marking (or an equivalent approved certification) are allowed to be registered. These draft regulations will contain specifications on the import licensing, labeling requirements, and post-market obligations of the license holder. Procedures for reporting and handling of adverse events and other post-market surveillance activities are likely to be established.

The introduction of regulations for medical devices in South Africa will also make it necessary to establish a local certification authority. It will be impossible, from both financial and geographic considerations, to rely on European certification authorities if medical device regulations are not to prejudice local small and medium size enterprises, which typically operate on small budgets. 


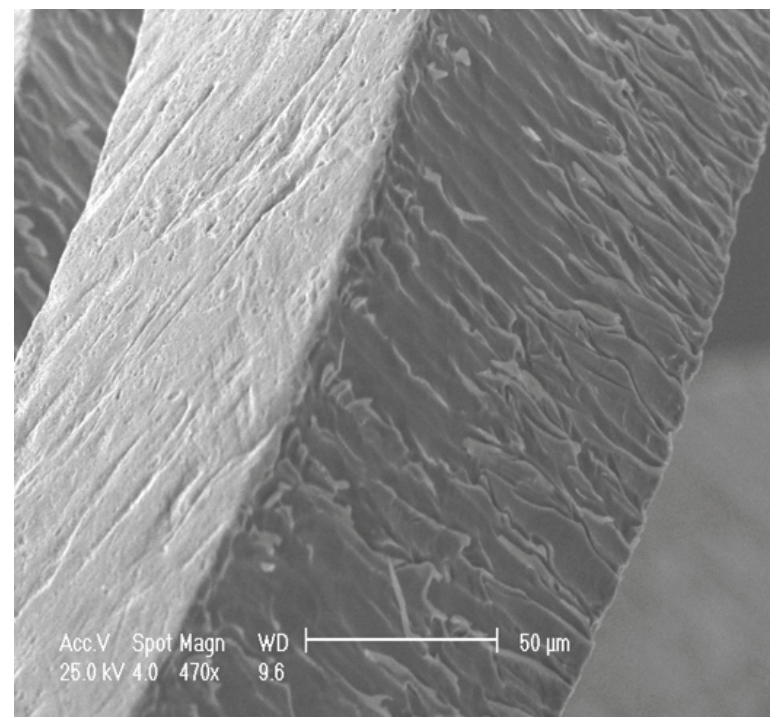

Figure 1a: Stent strut cut with Nd:YAG laser (Courtesy of Rofin-Baasel)

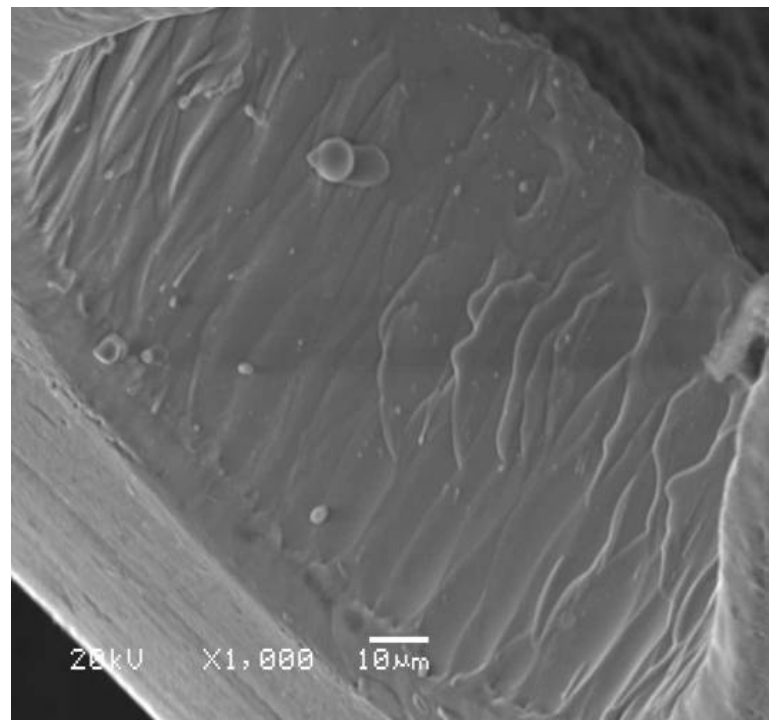

Figure 1b: Stent strut cut with fibre laser (Courtesy of Rofin-Baasel) 


\section{Case study for process improvement through better tools}

The progress made in manufacturing over the past decade can best be illustrated by the advances made with regard to advanced materials and manufacturing processes. Figure 1 shows the walls of a laser-cut stent. Stents are small scaffolding devices made from stainless steel 316L, shape memory alloys such as Nitinol, or co-alloys. The wall of the stent shown in Figure 1a was cut with an Nd:YAG laser, whereas the wall of the stent in Figure 1b was cut with a fibre laser. Although the magnification between Figures $1 \mathrm{a}$ and $1 \mathrm{~b}$ is different, it can be seen that the surface roughness of the stent wall cut with the Nd:YAG laser is considerably rougher than in the case of the fibre laser cut stent wall. Nd:YAG lasers were the tool of choice from the beginning of commercial stent cutting until just a few years ago. Their ability to focus into a spot size of several hundred micrometers diameter, and the repeatability of the laser operation, meant that automated stent cutting out of small diameter metal pipes was possible. With the market introduction of fibre lasers of hundreds of watts of output power over the past five years, it became possible to install fibre lasers for stent cutting instead of Nd:YAG lasers. The usage of fibre lasers is highly attractive, due to this laser beam's ability to focus into an even smaller spot size than Nd:YAG lasers. Strut widths as small as 10 micrometers can be achieved (Figure 2). This property then enables a stent designer to create even more filigree struts and curvatures (Figure 3 ). Another example of the degree of freedom given to designers by the introduction of stent cutting with fibre laser is shown in Figure 4.

\section{Processing of advanced materials}

Often when advanced materials are developed for particular applications, conventional machining and processing techniques cannot be employed. Microactuators for endoscopic surgery might have to be generated from shape memory alloys. However, forming or joining such materials is very challenging because the materials' properties may not be lost or destroyed during the machining process.

In a truly baseline investigation of the weldability of commercially available binary nickel-titanium shape memory alloys using an Nd:YAG laser, Haas [6] analyzed the behaviour of 50.5 at-\% and 48.5 at-\% containing Titanium (henceforth referred to as $\mathrm{Ni}_{51} \mathrm{Ti}$ alloy and $\mathrm{Ni}_{49} \mathrm{Ti}$ alloy). The author carried out his investigations with an eye on micromachining shape memory alloys in sheet-form; he therefore selected sheet metal thickness for both alloys of $0.5 \mathrm{~mm}$ and $0.17 \mathrm{~mm}$. The author documented that the laser-welded martensitic $\mathrm{Ni}_{49} \mathrm{Ti}$ alloy retained its shape-memory effect up to a strain of $6 \%$ without failure. The laser-welded joints exhibited a free recovery with an amnesia of $0.3 \%$. The ultimate tensile strength of the laser-welded region was $600 \mathrm{MPa}$, compared to $1200 \mathrm{MPa}$ of the base material. This reduction was attributed to the formation of $\mathrm{Ti}_{2} \mathrm{Ni}$ precipitations along the grain boundaries. The $\mathrm{Ni}_{51} \mathrm{Ti}$ alloy exhibited an ultimate tensile strength of $820 \mathrm{MPa}$ and a full elastic range of $7 \%$ strain, with a permanent set of $0.15 \%$. The author concluded that Nd:YAG laser-welding is a suitable joining process for nickel-titanium shape-memory alloys. 


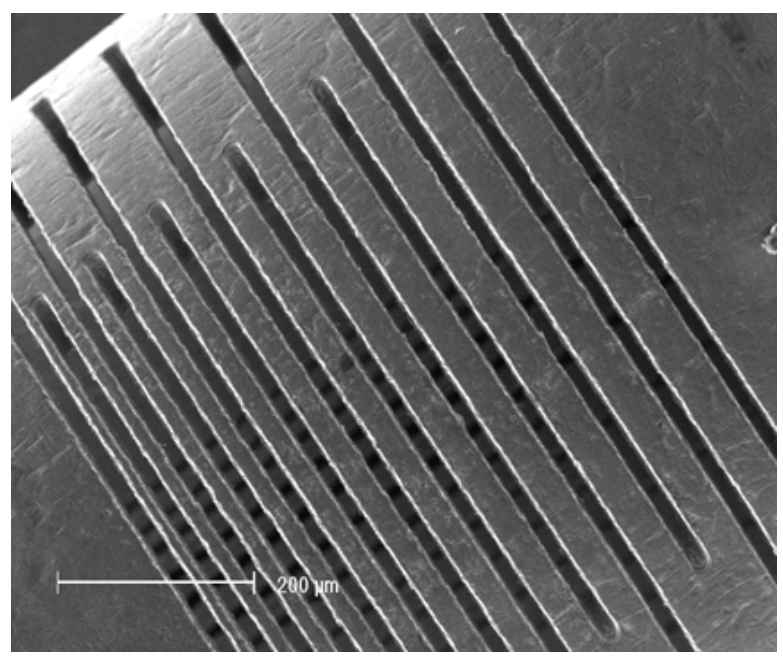

Figure 2: Achievable strut width is 10 micrometers (Courtesy of Rofin-Baasel)

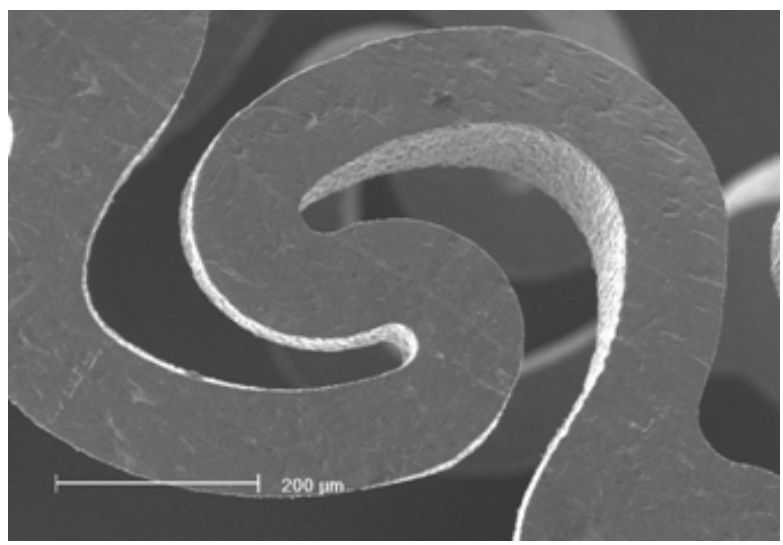

Figure 3: Laser-cut spiral in stent (Courtesy of Rofin-Baasel)

\section{Training people - Education}

Looking at the education of engineers, this approach to (biomedical) manufacturing carries many implications for the engineering qualification. First, an understanding of the complexity of a biological system must be conveyed. While the system's mechanisms and demands find some simple analogies for pulsating flows (heart, organs, and muscles) or statics (skeleton), an analogy to the prevention of restinosis 
formation by means of drug-eluting stents is much more complex. The complexity of a biological system can be illustrated from the area of orthopaedics by complications after hip replacements. Some patients are at risk of developing heterotopic ossification, a non-malignant overgrowth of the bone [7]. Calcification is another complication that can develop after hip replacements.

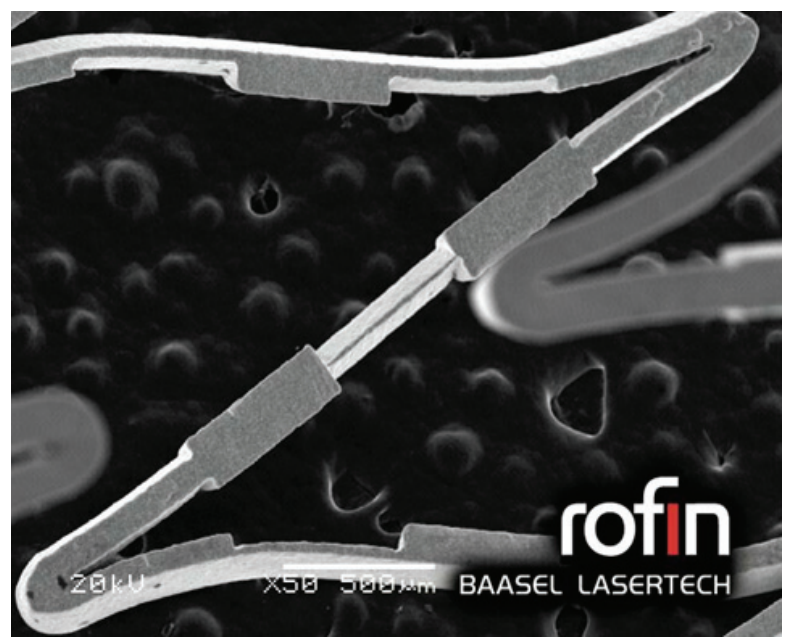

Figure 4: An example of the available degree of freedom for stent design (Courtesy of Rofin-Baasel)

Further, the manufacturing engineer must be taught to prevent massive work-inprocess and build-up of inventory. To accomplish this, he must gain an appreciation for the economical constraints imposed by inventory build-up and the risks introduced when machining or design errors are identified only after products have been sold and large inventories of defective components or products have been built-up.

This concept of "lean thinking" can be taken further than just the engineering level. Medical doctors at Flinders University Hospital in Adelaide, Australia, led by BenTovim et al [8], identified new paths for redesigning patient treatment and care. This group has implemented a lean approach to hospital care that enabled them literally to reduce the number of patients dying in their care. Their starting point was to observe the path (flow) of the patient through the hospital from the patient's first presentation to being discharged. This approach leaves behind the "departmental thinking" and maps the horizontal way that a patient (i.e., customer) takes through the vertically-organized departments and specialties in a hospital. Contrary to the general perception that in an emergency room one "does not know what comes through the door next", the authors were able to increase their emergency room throughput by $20 \%$ and also accelerate turn-over in wards by $20 \%$. 
This was accomplished by standardizing procedures and by optimizing the patient's "flow" through the organization.

Health care as a whole (to which biomedical manufacturing is party) therefore must be open to alternative "production" approaches. Teaching engineering at higher education institutions in particular must instill in tomorrow's engineers the ability to look at a process from a customer's (i.e., patient's) perspective. Apparently purely economical considerations about work-in-process and inventory build-up carry engineering penalties, in the form of rework and recalls, continuous prioritizing of products in the production queue, and reduced capacity for new product development.

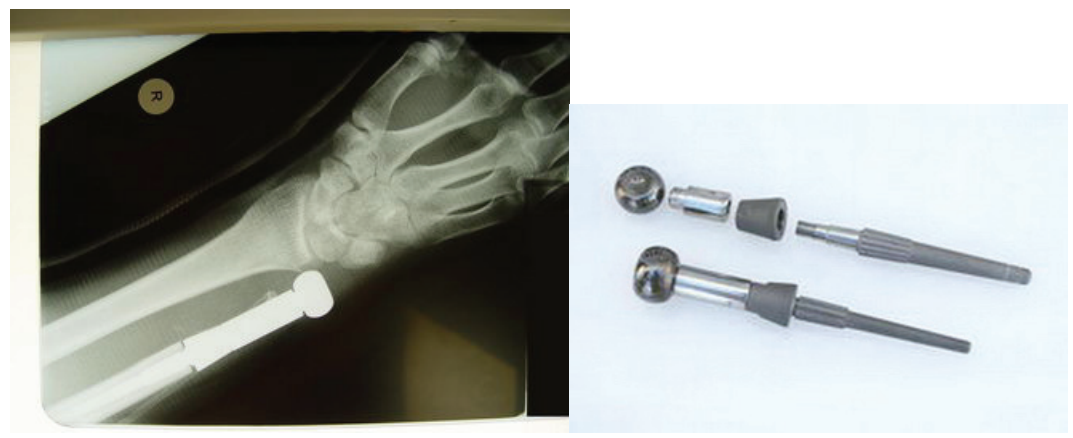

Figure 5: Orthopaedic Distal Ulna Arthroplasty (Courtesy of ISIQU)

\section{Case study in orthopaedics}

Replications of almost the entire human skeleton have been developed over the past 20 years, and there is a wide range of OEMs from all over the world to choose from. The most widely known examples of orthopaedic implants are probably titanium screws for bone fixation and hip and knee replacements. Figures 5 and 6 show arthroplasties of the Distal Ulna and the Distal Radius respectively. These arthroplasties were developed to replace cancerous bone material. As the extent of the progression of the disease in a patient must determine the dimensions of the implants, these implants are customized to the patient and are "once-off" parts. Because of the customization of the implants and the nature of the life-threatening disease, there literally is no time for extensive trials. These implants therefore are not subject to regulation approval. This setup enables the manufacturer of these arthroplasties to respond to customer demands very quickly.

Product improvement in orthopaedics in the future clearly must consider demographic developments in many countries. As their populations age, the number of (partial or total) hip and knee replacements is going to increase. An area which is going to attract considerable attention is the behaviour of such replacements when subjected to trauma (a person falling or being hit by a vehicle). The forces on orthopaedic implants in accidents are difficult to simulate in a dynamic situation, owing to lack of data about muscles, tendons, skeleton, and their interaction. The 
behaviour of such bone / arthroplasty systems in cases where they are subjected to transient high strain-inducing loads is unknown and must be researched.

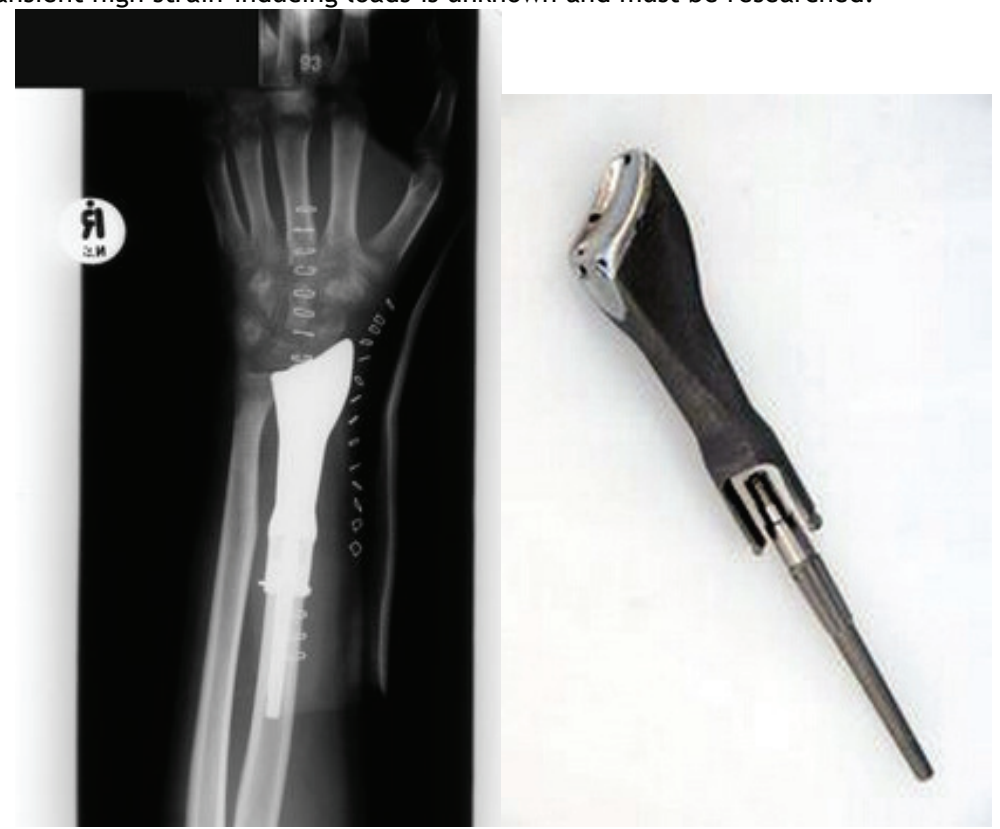

Figure 6: Orthopaedic Distal Radius Arthroplasty (Courtesy of ISIQU)

\section{CONCLUSIONS}

The introduction of medical devices regulation in the South African medical devices market will lead to considerable market realignment and defragmentation. The opportunity is presented to focus on the purpose of a manufacturing company (to make the products that the customer wants). The need for a local certification authority was identified. It was concluded that the application of lean principles in the still-developing South African biomedical industry offers great advantages in allocating financial and personnel resources.

It was further concluded that process improvements extend beyond technological improvements in a manufacturing environment. Seemingly unpredictable environments offer opportunities for standardization, leading to improved process efficiencies.

Great opportunities and responsibilities rest with higher education institutions in the preparation of students (people), through appropriate curricula, to meet the demands of the biomedical industry. The tools available to achieve "zero defect", interdisciplinary product development, should be part of the education of tomorrow's engineers. 


\section{ACKNOWLEDGEMENTS}

The author would like to thank Dr Keith Schlagbauer from Frost \& Sullivan for his valuable input and discussions, as well as Dieter Mairhoermann from Rofin-Baasel and Dr George Vicatos from ISIQU for the information and images provided.

\section{REFERENCES}

[1] http://www.census.gov/epcd/naics02/def/NDEF31.HTM

[2] Food and Drug Administration, Good manufacturing processes, Code of Federal Regulations Title 21, Volume 8 Medical Devices, revised as of April 1, 2006.

[3] Womak, J., Jones, D., Roos, D., The machine that changed the world" Rawson Associates, 1990.

[4] Fronstin, P., MacDonald, J., Rising Costs Cause More Shifts in Use of Health Care System, Employee Benefits Research Institute, ISSN: 1085-4452/90, 24 October 2007.

[5] Schlagbauer, K., Strategic Assessment of the Healthcare Industries in Key SubSaharan African Countries, SAMED presentation, Cape Town, 5 June 2007.

[6] Haas, Th., Laserstrahl-Schweißen von NiTi-Formgedächtnislegierungen, Dissertation, Forschungszentrum Karlsruhe, Wissenschaftliche Berichte, FZKA 5709, April 1996.

[7] Padgett, Douglas E. MD, et al. The Efficacy of 500 CentiGray Radiation in the Prevention of Heterotopic Ossification after Total Hip Arthroplasty: A Prospective, Randomized, Pilot Study. Journal of Arthroplasty, September 2003, Vol. 18, No. 6, pp. 677-686.

[8] Ben-Tovim D.I., Bassham J.E., Bolch D., Martin M.A., Dougherty M., Szwarcbord M., Lean thinking across a hospital: Redesigning care at the Flinders Medical Centre, Australian Health Rev. 2007 Feb;31(1):10-5. 